\title{
Modelling of Gas Tungsten Arc Welding Pool under Marangoni Convection
}

\author{
Steven Wang, Roy Nates, Timotius Pasang, Maziar Ramezani*
}

Department of Mechanical Engineering, Auckland University of Technology, New Zealand

Copyright (C) 2015 by authors, all rights reserved. Authors agree that this article remains permanently open access under the terms of the Creative Commons Attribution License 4.0 International License

\begin{abstract}
Due to lack of comprehensive experimental studies on welding processes, and to better understand the mechanisms behind these processes, especially the weld pool shape variations suspected due to Marangoni Effect or surface tension shear stress, a two-dimensional simulation model was developed to study the physics of gas tungsten arc welding (GTAW). Experimental spot-welds on Ti-5Al-5Mo-5V-3Cr was carried out to compare to the model for crucial clues such as, the magnitude of Marangoni convectional stress that is difficult to determine experimentally; and to estimate the Enhancement Factor, an artificial parameter incorporated into the model proven to account for any discrepancies between simulated results and experimental weld pool shapes, due to lack of viscosity temperature dependent data as well as flow instabilities. The model confirmed that Marangoni Convection is indeed the most dominant force in shaping the weld pool, followed by thermal buoyancy force and electromagnetic force. As the investigation went on, the validity of past welding simulations assuming a constant flow scheme was examined, concluding with the recommendation of applying a laminar flow regime at the initial welding times and turbulent flow with elapsing welding time to effectively eliminate simulation inaccuracies.
\end{abstract}

Keywords Fluent, GTAW, Marangoni Convection, Simulation, Welding

\section{Introduction}

With several different fusion welding processes, the melted weld pool profile which ultimately solidifies to form the fusion zone, diverging greatly by a wide variety of factors, e.g. base material, workpiece size, machine setups and extensive range of other process variables. For each distinctive welding setup, the weld pool geometry could vary considerably, and thought to be largely dependent on the hydrodynamics of the weld pools [1].

During the last couple of decades, the weld pool characteristics were broadly studied, these included experimental studies and more recently numerical studies involving CFD simulations.

Experimental studies on weld pool behaviours were largely focused on the flow characteristics, but were rather limited due to difficulty that light could not travel through liquid metal or poor opacity, not to mention the tight space as weld pools are generally in the order of millimetres, coupled with extremely high temperature nature of the welding processes, all made measuring the flow near impossible. Reported researches in the area of Marangoni convection were essentially owed to the validation of the ability of surface active elements within the workpiece to modify the flow pattern [2], allowing some understanding of the internal flow characteristics of the weld pool. Into the $21^{\text {st }}$ century, experimental studies were taken to the next level with the assistance of X-ray transmission devices, the internal flow could now be accurately captured in motion and examined in detail [3].

As for numerical studies, given the rapid development of CFD software packages, modern welding researchers could now be able to simulate welding processes with nearly unlimited possibilities, taking into account the flow regime e.g. laminar or turbulent, modelling the solidification stage, sensitivity analysis on wide variety of operating parameters, effect of shielding gas and so on. Overall, previous numerical studies could be divided into the following assumption/basis groups: 2D or 3D, free or flat surface, incorporation of solidification stage and laminar or turbulent flow. As for the model orientation, 2D and 3D models did not deviate much in terms of capabilities to perform enormous range of studies on the weld pool behaviours, and showed identical results,

Bethier et al. [4] developed a two-dimensional axial symmetric model for tungsten inert gas (TIG) and active TIG (A-TIG) welding. Flow behaviour in the meting pool on a stainless steel disc (304L) melted by a stationary heat source were presented to show the influence of Marangoni convection combined with Lorentz forces. Xia et al. [5] developed a FE model to describe and reflect the flow in the molten pool with considering the Marangoni convection on 
plasma direct metal forming process. The model revealed that the velosity of the front part of the pool is a little slower than aft part. Marangoni convection reinforced the convection and enhanced the heat transfer. Sandor et al. [6] showed that a thin layer of silica flux leads to an increased depth of weld penetration during activated TIG welding of Armco iron. The oxygen-content is found higher in the solidified weld metal and it was linked to the increased depth of penetration through the reversed Marangoni convection. It was theoretically shown for the first time that the basic reason of the reversed Marangoni convection is the phenomenon called "surface phase transition", leading to the formation of a nano-thin $\mathrm{FeO}$ layer on the surface of liquid iron.

With the above information in mind, the debate on $2 \mathrm{D}$ or $3 \mathrm{D}$, free or flat surface and incorporation of solidification would be settled; there would be little difference in terms of result accuracy [7]. Whereas, as for the flow regime, almost all welding researches had either applied laminar flow regime or turbulent flow assumption both with enhancement factors to account for under calculations of momentum and energy, in order to get good agreements with experimental results [8].

This research group believe that Marangoni Effect is the dominant force in weld pool shaping; also that the "constant" laminar or turbulent flow assumption would be fundamentally flawed, since fluid flow should not be consistently laminar or turbulent all the way through as done by past numerical studies; and to better understand the weld pool behaviours, a two-dimensional simulation model was constructed in Fluent ${ }^{\circledR}$ based on stationary arc GTAW welding conditions. In addition, GTAW welding experiments were also performed on titanium alloy Ti-5Al-5V-5Mo-3Cr as reference data for the numerical results validation.

\subsection{Marangoni Convection in Weld Pools}

\section{Marangoni Effect}

The Marangoni Effect or thermo-capillary effect, is the effect of mass transfer of fluids due to surface tension gradient; it was first identified by physicist James Thomson in 1855, by the phenomenon "tears of wine" [9]. Not long after the discovery, the Italian Physicist Carlo Marangoni studied this phenomenon in his doctoral thesis and was published in 1865; the general physical effect is then name after him [10].

The concluding remark was that liquid with higher surface tension would pull more strongly on the surrounding liquid than the one with lower surface tension, since water has a higher surface tension than alcohol, this surface tension gradient would cause the liquid to flow away from regions of lower surface tension (the alcohol) [10]; hence as observed, water is convectively and naturally flowing outward to the glass.

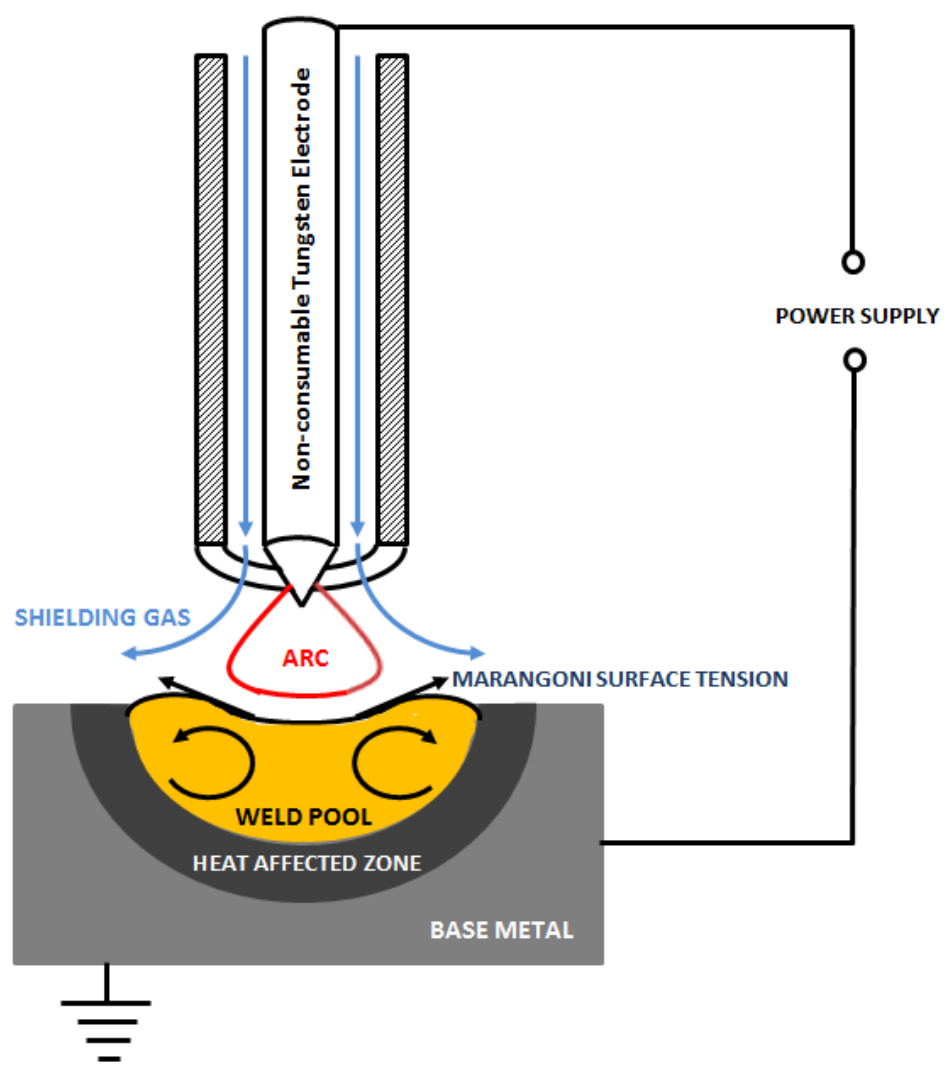

Figure 1. Schematic diagram of GTAW process with negative surface tension temperature gradient 


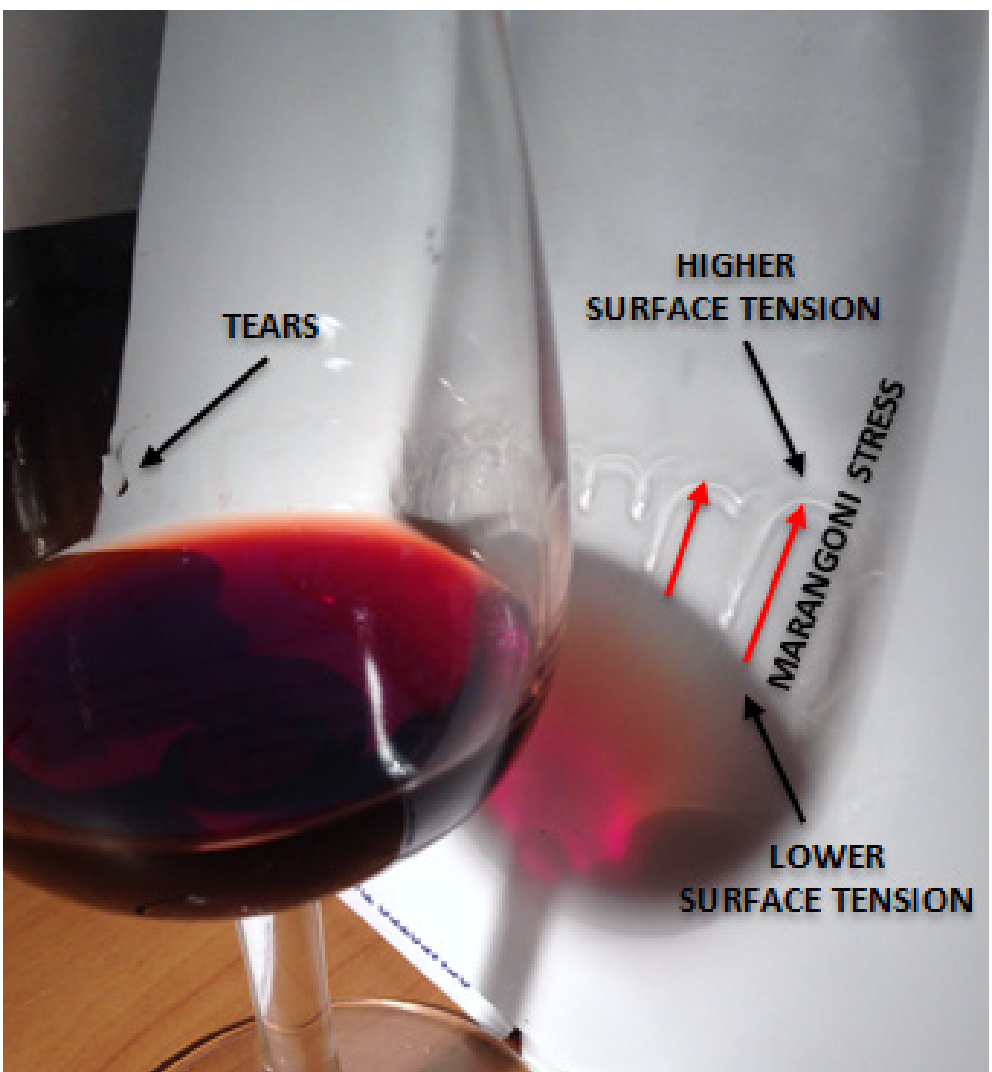

Figure 2. Photo of tears of wine and illustration of Marangoni Effect

\section{Marangoni Number}

The Marangoni number is a dimensionless number describing the relative importance of surface tension forces to viscous forces [9]. It is illustrated in the following form:

$$
M a=-\frac{d \gamma}{d T} \cdot \frac{L \Delta T}{\mu \alpha}
$$

where $\gamma$ is the surface tension stress, $T$ the temperature of the weld pool, $L$ the characteristic length, $\alpha$ the thermal diffusivity of the workpiece, and $\mu$ the dynamic viscosity of the material.

This number was established in an attempt to evaluate and quantify the Marangoni Effect, mostly used in mass transfer applications such as dopant distribution in silicon fibres and semi-conductors [9]; as for welding applications, the more relevant surface tension temperature gradient, the $d \gamma / d T$ term is of great importance, values can range from negative to positive. Although the values for the surface tension temperature gradient are somewhat exceedingly small, usually in the order of $\pm 5 \times 10^{-4} \mathrm{~N} / \mathrm{m} \cdot K$, whereas this decimal number along with the sign change would have crucial implications to the weld pool geometry because of the very distinctive flow behaviours [11].

\section{Surface Tension Temperature Gradient}

As mentioned before, the weld pool shape is believed to be very dependent on Marangoni convection, in the centre of it all, is the surface tension temperature gradient. For welding processes, the workpiece would contain some degree of impurities, such as oxygen and sulphur found in steels; during welding, these impurities were discovered to be very 'surface active', altering the surface tension gradient together with temperature, thus making the term extremely complex to formulate [12].

To make things simpler and easier to comprehend, as a general trend, the surface tension temperature gradient would be altered by the amount of surface active elements present along with a critical temperature to change the sign of $d \gamma / d T$, resulting in three scenarios of convective fluid flow [13]:

(1) Negative $\boldsymbol{d} \boldsymbol{\gamma} / \boldsymbol{d} \boldsymbol{T}$ when surface active element concentration is low; 

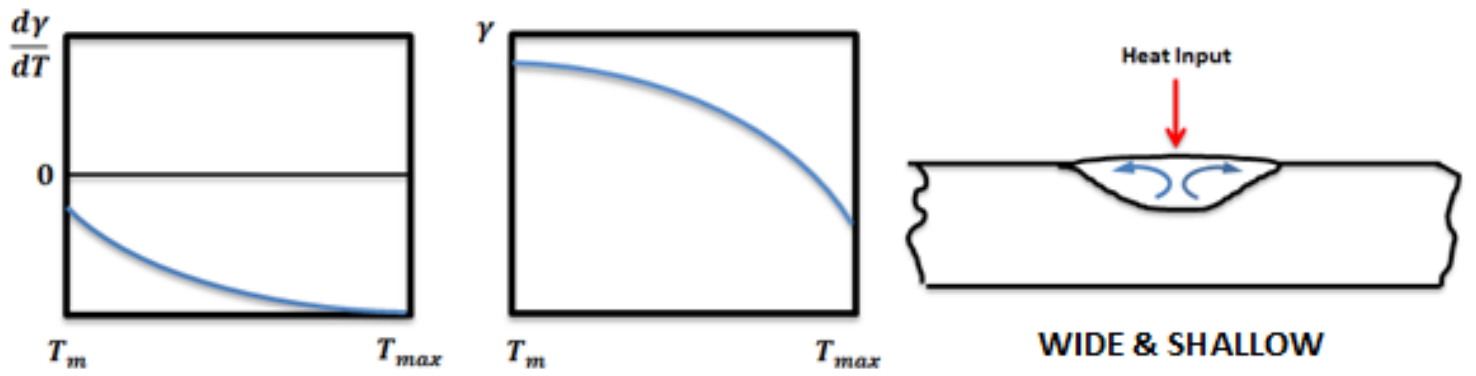

WIDE \& SHALLOW

Figure 3. Wide and shallow pool by negative gradient

This would lead to the surface temperature greater than the critical temperature, thus surface tension is lower in the high temperature region, the pool centre; therefore according to Marangoni convection theories, liquid metal would experience an outward flow from the pool centre.

(2) $\boldsymbol{d} \gamma / \boldsymbol{d} \boldsymbol{T}$ can be both positive and negative across the pool when surface active element concentration is increased;
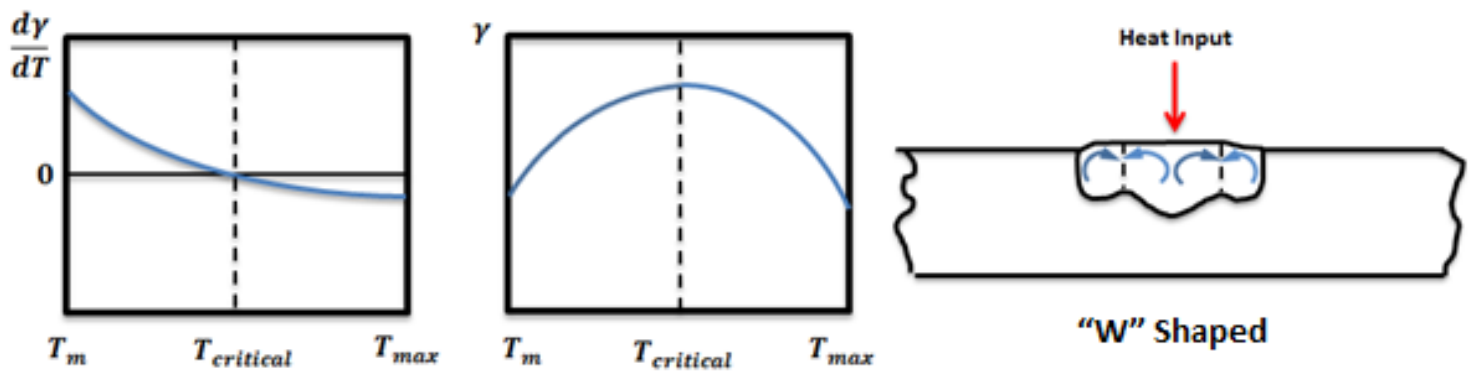

Figure 4. "W" shaped pool by pool boundary not yet surpassing the critical temperature

Under this scenario, the critical temperature sits in between the pool centre and boundary, inducing a zero $d \gamma / d T$ in the pool at this temperature where the surface tension is highest. So as the temperature at the pool centre would be higher than the critical temperature, a negative $d \gamma / d T$ would be initiated, thus outward flow; likewise at the pool edge, its temperature (melting point) would be lower than the critical temperature, a positive $d \gamma / d T$ would be encouraged, hence inward flow. By combining these two distinctive flow patterns, a "W" or "dog-bone" shaped pool would be created.

(3) Positive $\boldsymbol{d} \boldsymbol{\gamma} / \boldsymbol{d} \boldsymbol{T}$ when surface active element concentration is further increased;
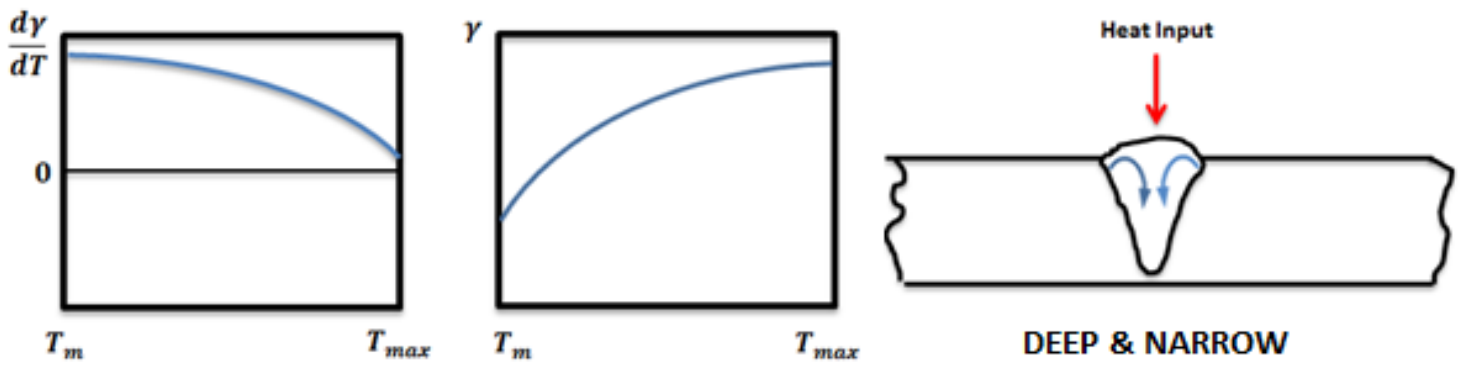

DEEP \& NARROW

Figure 5. Deep and narrow pool by positive gradient

Now if the surface active element concentration is high enough, that the entire surface temperature is now lower than the critical temperature, then surface tension is now higher in the high temperature region, the pool centre; this would reverse the flow pattern completely to inward flows to the pool centre. 


\subsection{Forces in GTAW}

\section{Surface Tension Force}

As discussed previously, surface tension force, or Marangoni convection does play an exceptional role in weld pool formation. Even though this critical temperature is vastly unknown for most materials, but with the absence of surface active elements, the surface tension temperature gradient would be negative for most materials [13]. In other words, wide and shallow pool shapes would be observed for most materials because a negative gradient would induce outward flow patterns from the pool centre to the pool edge; hence the surface temperature had typically fully surpassed the critical temperature for outward flow.

However with the surface active elements into the equation, things do get a lot more complicated; the weld pool fluid flow would be altered dramatically with addition of surface active elements into the material, as well as changing concentration of the surface active element [13].

As suggested by Limmaneevichitr and Kou [14] in their experimental work, by adding surface active element of $\mathrm{C}_{2} \mathrm{H}_{5} \mathrm{COOK}$ while keeping all other process parameters constant, the surface tension temperature gradient of $\mathrm{NaNO}_{3}$ changed from negative to positive, and so did the flow pattern from outward to inward. Essentially, their studies on the surface active elements and weld pool behaviour were based on one significant work produced by Sahoo et al. [15] where they had given the issue a mathematical treatment as following:

$$
\begin{aligned}
& \frac{d \gamma}{d T}=\left.\frac{d \gamma}{d T}\right|_{o}-R \Gamma_{S} \ln \left(1+K a_{i}\right) \\
& -\frac{\boldsymbol{K} \boldsymbol{a}_{i}}{\left(1+\boldsymbol{K} \boldsymbol{a}_{i}\right)} \frac{\Gamma_{S}\left(\Delta \boldsymbol{H}^{o}-\Delta \overline{\boldsymbol{H}}_{i}^{M}\right)}{\boldsymbol{T}} \\
& K=k_{1} \exp \left[\frac{-\Delta H^{o}}{R T}\right]
\end{aligned}
$$

where $d \gamma /\left.d T\right|_{o}$ denotes surface tension temperature gradient for pure metal, $R$ gas constant, $\Gamma_{\mathrm{S}}$ surface excess at concentration, $\Delta H^{o}$ standard heat of absorption, $\Delta \bar{H}_{i}^{M}$ partial molar enthalpy of species mixing in the solution, $k_{1}$ constant to entropy of segregation and $a_{i}$ activity of the element in material.

By having this mathematical model, it does give welding researchers some insights into ways of surface active elements in influencing the surface tension force, hence weld pool fluid flow and ultimately the pool geometry.

However, it is only useful in determining the surface tension temperature gradient for one active element at a time; this would obviously be the major drawback of this approximation. For instance commonly for steels, two main active elements would be present, oxygen and sulphur, but only one element could be assessed each time, and the other element would be ignored. This is mainly why most welding researches would only use constant surface tension temperature gradient values, also because that there are just so many things happening at once during the weld pool formation.

\section{Electromagnetic Force}

For a GTAW process, electromagnetic force would be present. Since electric current is flowing through the conductor (workpiece), a magnetic field would be produced; as a result the liquid weld pool would be subject to this induced magnetic field, causing convective flow. Generally the flow direction would be inward referring to Kou \& Sun and their findings [16].
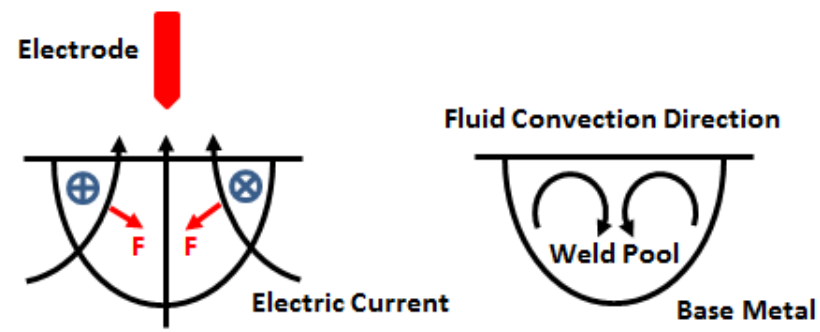

\section{Direction of Magnetic Field}

$\oplus$ Out of Paper

Into Paper

Figure 6. Schematic diagram of electromagnetic force acting in the GTAW weld pool (left); inward flow pattern (right); redrawn from Kou [17]

The electromagnetic force $\vec{F}_{e m}$ or Lorentz force, is governed by the equation below:

$$
\overrightarrow{\boldsymbol{F}}_{\text {em }}=\overrightarrow{\boldsymbol{J}} \times \overrightarrow{\boldsymbol{B}}
$$

where $\vec{J}$ and $\vec{B}$ are the current density vector and magnetic flux vector in the weld pool respectively.

Early studies of Kou and Sun [16] saw the development of a set of equations to accurately simulate the electromagnetic force with the aid of Maxwell's equations in reference to the Magneto-hydrodynamics approximation, for a three-dimensional axis-symmetric welding system under spot welding (stationary arc) conditions. The simulation was done for thick aluminium alloy AA6061 plate, for a current of $150 \mathrm{~A}$, voltage of $15 \mathrm{~V}$ and an assumed efficiency of $80 \%$, returned a $25 \mathrm{~cm} / \mathrm{s}$ maximum velocity in the weld pool. Thus the electromagnetic force would be considered quite significant in terms of magnitude in the weld pool.

Further studies were done by Kumar and DebRoy [18] in an attempt to accurately model the electromagnetic force in a GTAW weld pool, where considerations of base metal geometry, arc distance to workpiece, electrode current, arc plasma, current distribution were all taken into account; again the simulation was done for three-dimensional, axis-symmetric systems.

As for two-dimensional modelling of electromagnetic force in a weld pool, Shi et al. [19] applied the following equations by considering the forces separately in both axial and radial directions:

\section{Axial Direction}

$$
E M_{z}=\frac{\mu_{m} I^{2}}{4 \pi^{2} r^{2} z_{L}}\left[\left(1-\exp \left(-\frac{r^{2}}{2 \sigma_{j}^{2}}\right)\right]^{2}\left(\frac{z}{z_{L}}\right)\right.
$$




\section{Radial Direction}

$$
E M_{r}=\frac{\mu_{m} I^{2}}{4 \pi^{2} \sigma_{j}^{2}} \exp \left(-\frac{r^{2}}{2 \sigma_{j}^{2}}\right)\left[\left(1-\exp \left(-\frac{r^{2}}{2 \sigma_{j}^{2}}\right)\right]\left(\frac{z}{z_{L}}\right)^{2}\right.
$$

where $\mu_{m}$ is the magnetic permeability, $I$ the welding current, $z_{L}$ thickness of the workpiece, $\sigma_{j}$ effective current distribution parameter, $r$ and $z$ the radial and axial distance respectively.

\section{Buoyancy Force}

For any weld pool, the temperature in the pool centre would be higher than the temperature found at the pool boundary; and since the density of the liquid metal at a higher temperature would be lower, then as illustrated in Fig. 7, an upward buoyancy force would be created as at Point a; as for Point $b$ near the pool boundary, where the temperature would be considerably lower than at Point a, a downward force would be expected [20].
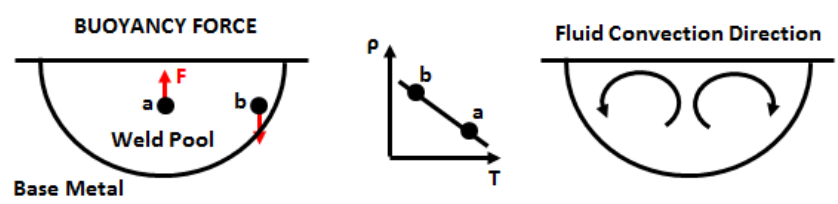

Figure 7. Schematic diagram of buoyancy force acting on the weld pool (left); density difference between point a and b (middle); outward flow (right). Redrawn from Kou [20]

The upward forces at the hotter regions coupled with downward force at the cooler regions would inevitably produce a convective shift of liquid metal originating from the centre to the pool edge, causing an outward flow situation as seen in Fig. 7 (right).

Buoyancy force could be calculated by Boussinesq approximation [21]:

$$
B=-\rho g \beta\left(T-T_{o}\right)
$$

where $\rho$ is the density of the liquid metal, $g$ the gravitational acceleration constant, $\beta$ thermal expansion coefficient, $T$ temperature of liquid metal and $T_{o}$ reference temperature which is normally the room temperature.

\section{ARC Plasma Force}

The arc plasma shear stress exists by the simple fact that the arc plasma contains kinetic energy as well as momentum [22]. When the arc plasma strikes the weld pool at the pool centre, an outward shear force would be exerted on the pool surface as shown in Fig. 8 (left). Similar to surface tension forces, this shear stress initiated from the pool surface would certainly drive outward convective flow of liquid metal as indicated in Fig 8 (right).

In most cases, the magnitude of the force generated by arc plasma would be the least significant amongst surface tension force, electromagnetic force and buoyancy force [23]. However, according to the study conducted by Matsunawa and Yokoya [24], the arc plasma force may be substantially increased for a long arc length $(8-10 \mathrm{~mm})$ welding process, as well as with excessively high welding current since the momentum and kinetic energy level would be raised drastically.
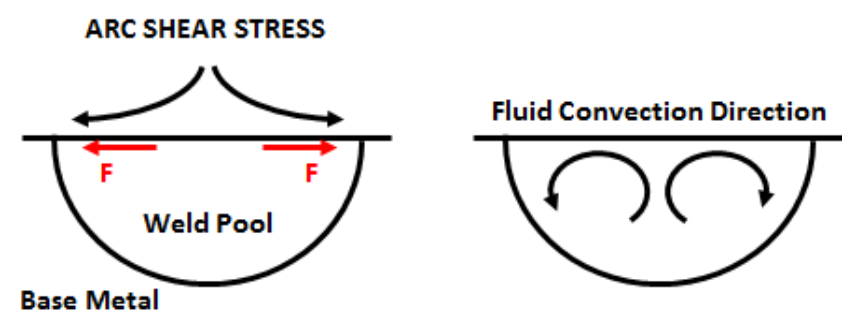

Figure 8. Schematic diagram of buoyancy force acting on the weld pool (left); density difference between point a and b (middle); outward flow (right). Redrawn from Kou [20]

\section{Numerical Modelling}

\subsection{Assumptions Made}

In numerical study conducted in this paper, the following assumptions were made:

(1). Two-dimensional transient heat transfer process

(2). Flat surface with no surface deformations;

(3). Standard k- $\varepsilon$ turbulent model (laminar flow also investigated);

(4). Fluid as incompressible Newtonian;

(5). Axisymmetric along the z-axis;

(6). Gas phase ignored (only solid and liquid phases);

(7). Gaussian distribution of the heat flux;

(8). Approximate change of latent heat of melting for materials as linear;

(9). Arc plasma force small enough to be ignored (low current level and short arc welding processes);

(10). Ambient temperature as $300 \mathrm{~K}$

(11). Ambient pressure at $101.325 \mathrm{kPa}$

\subsection{Governing Conservation Equations}

Confining to the above assumptions, the conservation equations resulting in the following forms [25]:

\section{Conservation of Mass}

$$
\frac{1}{r} \frac{\partial(r u)}{\partial r}+\frac{\partial v}{\partial z}=0
$$

\section{Conservation of Momentum in Axial Direction}

$$
\rho\left(\frac{\partial v}{\partial t}+\boldsymbol{u} \frac{\partial v}{\partial r}+\boldsymbol{v} \frac{\partial v}{\partial z}\right)=-\frac{\partial p}{\partial z}+\mu\left(\frac{\partial^{2} v}{\partial r^{2}}+\frac{\partial v}{r \partial r}+\frac{\partial^{2} v}{\partial z^{2}}\right)+S_{z}
$$

\section{Conservation of Momentum in Radial Direction}

$$
\rho\left(\frac{\partial u}{\partial t}+u \frac{\partial u}{\partial r}+v \frac{\partial u}{\partial z}\right)=-\frac{\partial p}{\partial r}+\mu\left(\frac{\partial^{2} u}{\partial r^{2}}+\frac{\partial u}{r \partial r}-\frac{u}{r^{2}}+\frac{\partial^{2} u}{\partial z^{2}}\right)+S_{r}
$$

\section{Conservation of Energy}

$\rho C_{p}\left(\frac{\partial T}{\partial t}+u \frac{\partial T}{\partial r}+v \frac{\partial T}{\partial z}\right)=\frac{\partial}{r \partial r}\left(k r \frac{\partial T}{\partial r}\right)+\frac{\partial}{\partial z}\left(k \frac{\partial T}{\partial z}\right)+S_{e}$ 
where $z, r, u, v, \rho, p, \mu, k, T$ and $C_{p}$ are the axial distance, radial distance, radial velocity, axial velocity, density of material, pressure, viscosity of liquid metal, thermal conductivity, temperature of liquid metal, and specific heat respectively. In addition, $S_{z}$ and $S_{r}$ are the non-standard momentum source terms in the axial and radial direction, topped with $S_{e}$ the energy source term.

\subsection{Momentum \& Energy Source Terms}

\section{Axial Momentum Source \& Sink Term}

$$
S_{z}=B+E M_{z}+A v
$$

where,

$$
\begin{gathered}
B=-\rho g \beta\left(T-T_{o}\right) \\
E M_{z}=\frac{\mu_{m} I^{2}}{4 \pi^{2} r^{2} z_{L}}\left[\left(1-\exp \left(-\frac{r^{2}}{2 \sigma_{j}^{2}}\right)\right]^{2}\left(\frac{z}{z_{L}}\right)\right. \\
A v=\frac{C_{l}\left(1-f_{l}\right)}{f_{l}^{3}+C_{s}} v
\end{gathered}
$$

where the first two terms represents the momentum sources, $B$ as the buoyancy force, $E M_{z}$ as the electromagnetic force in the axial direction, these two terms were explained before. The third momentum sink term is there to ensure that the velocity disappears in solid cells and appears in liquid cells. The determination of whether a cell would be solid or liquid is by $f_{l}$ the liquid fraction; the two constants were chosen deliberately to be $C_{l}$ large enough and $C_{s}$ small enough, to avoid the division by 0 when the liquid fraction is 0 in the solid. In the liquid zone, the sink term would fade away and a velocity field is attained by the other momentum source terms [26].

\section{Radial Momentum Source \& Sink Term}

$$
S_{r}=E M_{r}+A u
$$

where,

$$
\begin{gathered}
E M_{r}=\frac{\mu_{m} I^{2}}{4 \pi^{2} \sigma_{j}^{2}} \exp \left(-\frac{r^{2}}{2 \sigma_{j}^{2}}\right)\left[\left(1-\exp \left(-\frac{r^{2}}{2 \sigma_{j}^{2}}\right)\right]\left(\frac{z}{z_{L}}\right)^{2}\right. \\
A u=\frac{C_{l}\left(1-f_{l}\right)}{f_{l}^{3}+C_{s}} u
\end{gathered}
$$

where buoyancy force is no longer applicable in the momentum source term, thus the source term would only contain electromagnetic force which was explained in Section $\mathrm{x}$; and similarly, the momentum sink term would take the same form as the one discussed in axial direction, except the velocity is now in the radial direction $u$.

\section{Energy Source Term}

For a welding process, the energy source term would account for the latent heat change during phase transformation, in this case from solid to liquid. Brent et al. [29] modelled the latent heat change as:

$$
S_{e}=-\left[\frac{\partial \rho \Delta H}{\partial t}+\nabla \cdot(\rho U \Delta H)\right]
$$

where $\Delta H$ is the enthalpy change and $U$ is the velocity vector.
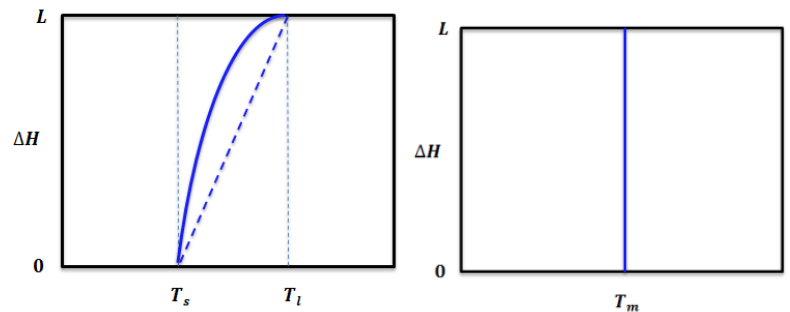

Figure 9. Change of latent heat of fusion for pure metals (left); for alloyed materials with the dashed line indicating the assumed linear profile (right)

The phase transformation for pure metals would occur sharply at the melting temperature $T_{m}$; while at the same time for alloyed materials, the phase change could happen during an interval, from the solidus temperature $T_{s}$ to liquidus temperature $T_{l}$ and the heat absorption is usually non-linear as shown in Fig. 9 [27]. By assuming the change of latent heat to be linear, some form of linearisation technique is needed.

By iterating Eqn 15, Patankar [27], Voller \& Swaminathan [28] were able to convert it into a linear equation:

$$
S_{e}=-\rho L \frac{\partial f_{l}}{\partial T} \frac{\partial T}{\partial t}
$$

The liquid fraction for alloyed materials would read:

$$
f_{l}=\left\{\begin{array}{cll}
0 & \text { if } & T \leq T_{s} \\
\frac{T-T_{s}}{T_{l-T_{s}}} & \text { if } & T_{s}<T<T_{l} \\
1 & \text { if } & T \geq T_{l}
\end{array}\right.
$$

where $T_{s}$ is the solidus temperature, $T_{l}$ the liquidus temperature and $L$ the latent heat of fusion.

\subsection{Velocity Boundary Conditions}

The velocity boundary condition is to be applied to the top surface, where surface tension temperature gradient would most definitely generate fluid flow not only on the weld pool surface, but also the pool interior.

\section{Top Surface by Marangoni Shear Stress}

Surface tension force would act in the tangential direction, and this force must be balanced by the viscous force subject to shear stress, the velocity boundary condition is therefore [19]:

$$
-\mu \frac{\partial u}{\partial z}=\frac{\partial \gamma}{\partial T} \cdot \frac{\partial T}{\partial z}
$$

where $\mu$ is the viscosity of liquid metal and $d \gamma / d T$ is worked as a single term to represent surface tension temperature gradient.

\section{Effect of Surface Active Elements}

According to previous discussions, the normal approach to surface tension temperature gradient would be inputting constant values for each material or welding process; however with the aid of Equation 2, optional studies on the surface active element could also be performed and was integrated into the model. 


\subsection{Temperature Boundary Conditions}

The Temperature boundary conditions were divided into two categories: the heat source coming from the arc acting on the top surface and heat losses to the ambient environment on all surfaces. It can be expressed as:

$$
k\left(\frac{\partial T}{\partial z}\right)=q_{\text {in }}-q_{\text {out }}
$$

where $q_{\text {in }}$ denotes the external arc heat source and $q_{\text {out }}$ as the heat loss to the environment by radiation and convection of surroundings.

\section{Arc Heat Source}

Only the top surface would experience external heat input, and this welding arc heat input could be modelled as Gaussian heat distribution as [19]:

$$
q_{i n}=\frac{\eta V I}{2 \pi \sigma_{j}^{2}} \exp \left(-\frac{r^{2}}{2 \sigma_{j}^{2}}\right)
$$

\section{Heat Losses}

All surfaces would be subject to convection and radiation heat transfer interacting with the ambient environment:

$$
q_{\text {out }}=h_{c}\left(T-T_{a}\right)+\sigma_{b} \varepsilon\left(T^{4}-T_{a}^{4}\right)
$$

where $h_{c}$ is the convection heat transfer coefficient, $T_{a}$ is the ambient temperature, $\sigma_{b}$ is the Stefan-Boltzmann constant and $\varepsilon$ the emissivity of material.

\subsection{Software Implementation}

Meshing was refined towards the origin (point $A$ ) on both $x$ and $y$ axes, these regions would be subject to intense heat flux (temperature field initiation) as well as surface tension effects (velocity field actuation), so that the model would iterate more accurately initially from these crucial areas, and the iterated results would be carried over to the succeeding internal cells; if the starting calculations were not comprehensive enough, then it would critically affect the quality of the subsequent calculations.

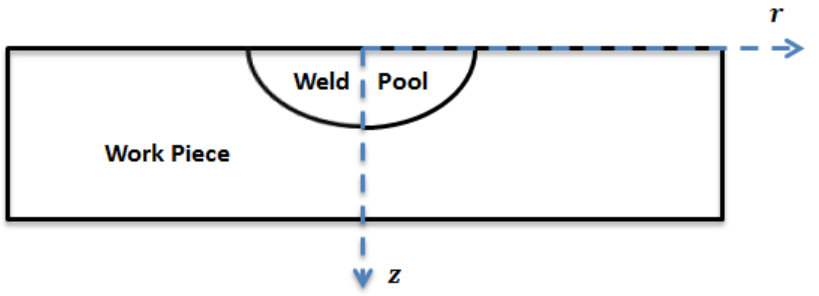

Figure 10. Schematic of workpiece and weld pool with reference axes

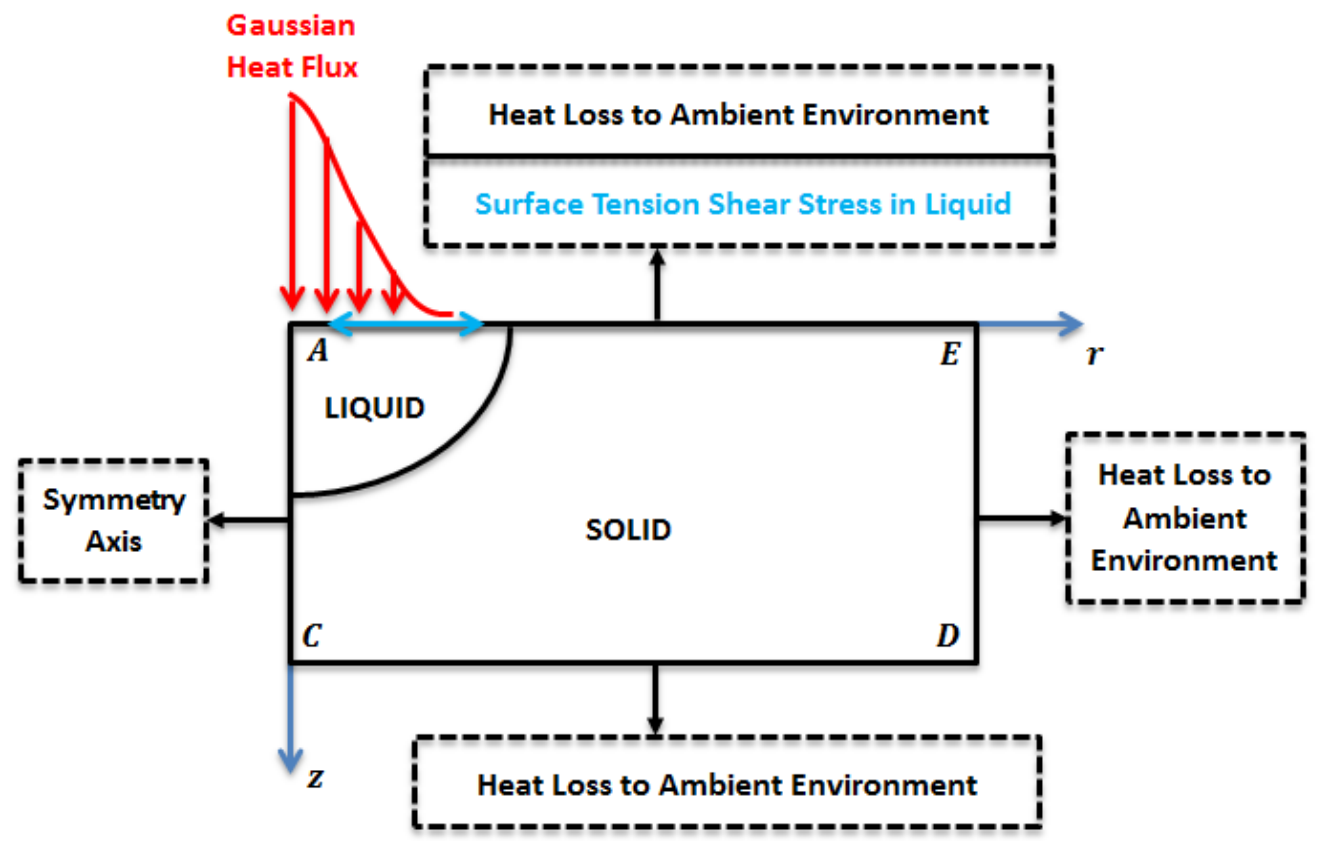

Figure 11. Schematic illustration of the simulation setup and temperature and velocity (surface tension force) boundary conditions. 


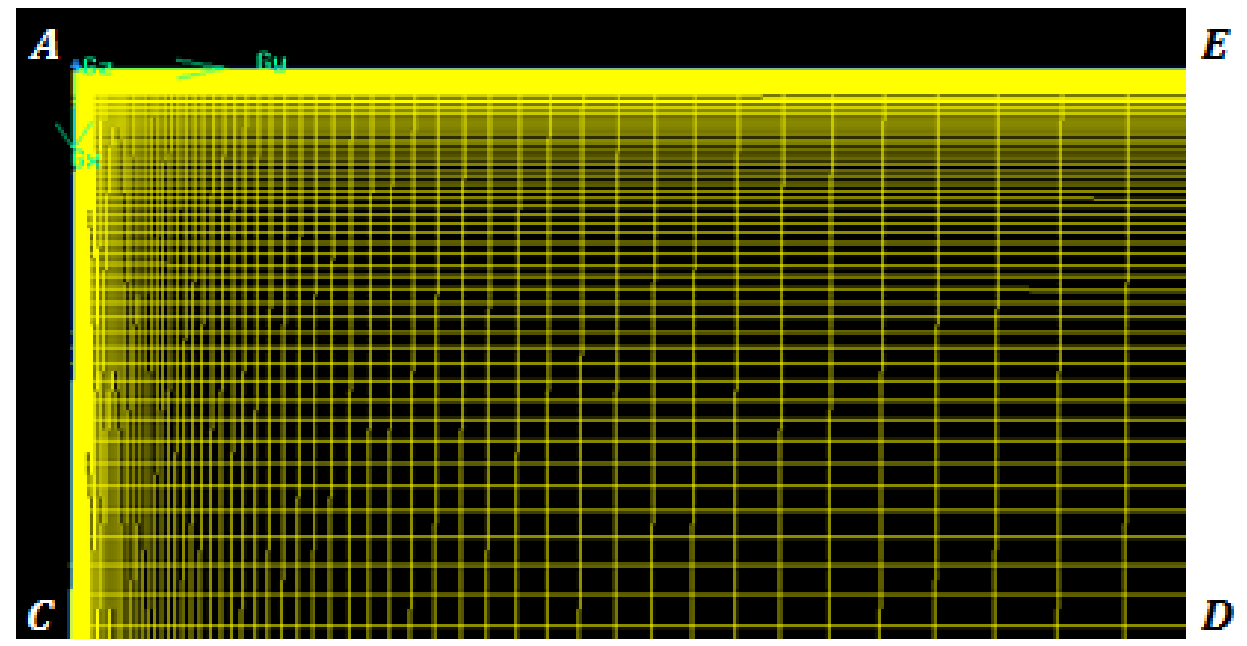

Figure 12. Capture of the general meshing algorithm

Calculations to solve the velocity-pressure coupling was handled by the SIMPLE convergence algorithm, an iteration process that pools the momentum and pressure in each time step, and gradually converging into the correct solution [27]. Moreover, the unique momentum and energy source terms were implemented and programmed into Fluent ${ }^{\circledR}$ as User-Defined Function (UDF), which was the core of the simulation programme.

\section{Model Validation}

\subsection{Enhancement Factor (EF)}

The use of enhancement factor was briefly outlined with respect to laminar or turbulent assumptions of the weld pool flow behaviour, in which whether the weld pool flow is laminar or turbulent is still not fully understood, even though reported literatures on weld pool simulations had been somewhat broadly studied. Nevertheless, enhancement factors were usually combined into the model to make up for underestimations on the momentum and energy calculations, and became the norm for welding simulations; so to get better agreement with the experimental results, regardless of the welding processes (GTAW, Laser welding, Electron Beam welding) [29]. This may be due to the fact that the flow process is confined to such a short time interval, yet also due to the highly unstable nature of the pool as well as plentiful forces acting on the welding pool that would further complicate the matter.

In short, the enhancement factor is applied to two material properties, liquid thermal conductivity and dynamic viscosity; these two terms were found to restrict the flow and alter weld pool geometries quite significantly (both width and depth) towards more desirable shapes compared to experimental data [8].

In this paper, the enhancement factor provides immediate and effective remedy in predicting the complex weld pool formation, but in a very primitive fashion with no clear guidelines.
Since the enhancement factor is utilised to cover for the lack of knowledge in the laminar or turbulence flow assumptions. Hong et al. [30] suggested that with a k- $\varepsilon$ turbulent assumption, a maximum enhancement factor of 16 should be used for a stationary GTAW process (spot welding). This paper does somehow offer a general starting point for the simulations ran in this project, with simulation runs by enhancement factors in steps of 1 (no enhancement), 2, 4, 8 and 16 .

Table 1. Operating conditions assumed in the reference case [31]

\begin{tabular}{|c|rl|}
\hline \multicolumn{2}{|c|}{ Operating Conditions } \\
\hline$\eta$ & 100 & $\%$ \\
$\sigma_{f}$ & 1.4 & $\mathrm{~mm}$ \\
$t$ & 5 & $\mathrm{~s}$ \\
\hline
\end{tabular}

Table 2. Material properties used in reference case for high speed steels [31]

\begin{tabular}{|c|rl|}
\hline Material Properties & & \\
\hline$\rho$ & 8100 & $\mathrm{~kg} / \mathrm{m}^{3}$ \\
$T_{m}$ & 1620 & $\mathrm{~K}$ \\
$\mu$ & 0.006 & $\mathrm{~kg} / \mathrm{m} \cdot \mathrm{s}$ \\
$k$ of solid & 22.9 & $\mathrm{~J} / \mathrm{m} \cdot \mathrm{s} \cdot \mathrm{K}$ \\
$k$ of liquid & 22.9 & $\mathrm{~J} / \mathrm{m} \cdot \mathrm{s} \cdot \mathrm{K}$ \\
$C_{p}$ of solid & 627 & $\mathrm{~J} / \mathrm{kg} \cdot \mathrm{K}$ \\
$C_{p}$ of liquid & 723.14 & $\mathrm{~J} / \mathrm{kg} \cdot \mathrm{K}$ \\
$L$ & $2.508 \times 10^{5}$ & $\mathrm{~J} / \mathrm{kg}$ \\
$\left.\frac{d \gamma}{d \tau}\right|_{。}$ & $-5.0 \times 10^{-4}$ & $\mathrm{~N} / \mathrm{m} \cdot \mathrm{K}$ \\
$\Gamma_{s}$ & $1.3 \times 10^{-8}$ & $\mathrm{kmole} / \mathrm{m}^{2}$ \\
$k_{1}$ & 0.00318 & \\
$\Delta \bar{H}^{0}$ & $-1.66 \times 10^{8}$ & $\mathrm{~J} / \mathrm{kmole}$ \\
$\Delta \bar{H}_{i}^{M}$ & 0 & $\mathrm{~J} / \mathrm{kmole}$ \\
\hline
\end{tabular}




\subsection{Reference Case}

The reference case chosen to be evaluated against was by Pitscheneder et al. [31], where they studied the effect of sulphur content as surface active elements on the weld pool shape and liquid metal flow patterns. The reason for the selection is quite obvious, the paper had both experimental and simulation results, it was done under stationary arc conditions, and the effect of surface active elements in their model was also presented. Although it was under Laser welding, but the only difference in the physical model compared to GTAW would the absence of electromagnetic forces, hence the simulation was done with omission of this force accordingly. Strangely enough, the material used in the reference case was high speed steels, with varying level of sulphur concentrations; nonetheless, the material was implemented into the proposed model.

\subsection{Comparisons with Reference Case}

In the $1900 \mathrm{~W}$ scenario, Pitscheneder et al. [31] employed an enhancement factor of 4 , and the proposed model had identical results when EF was set to 4. However, in both cases, the weld pool was slightly wider and shallower with their experimental results. If the power was adjusted up to $3850 \mathrm{~W}$ in the second scenario, good agreement with both the experimental and numerical results were gained, but with $\mathrm{EF}$ at 6 opposing to 7 used in the reference case. As for the $5200 \mathrm{~W}$ power setting scenario, the weld pool width is wider than the reference case, whereas the penetration conformed to the reference case quite well. Overall, the simulation results settled quite well with the reference case, this would permit confidence in the developed codes that is well validated for Marangoni driven welding simulations.
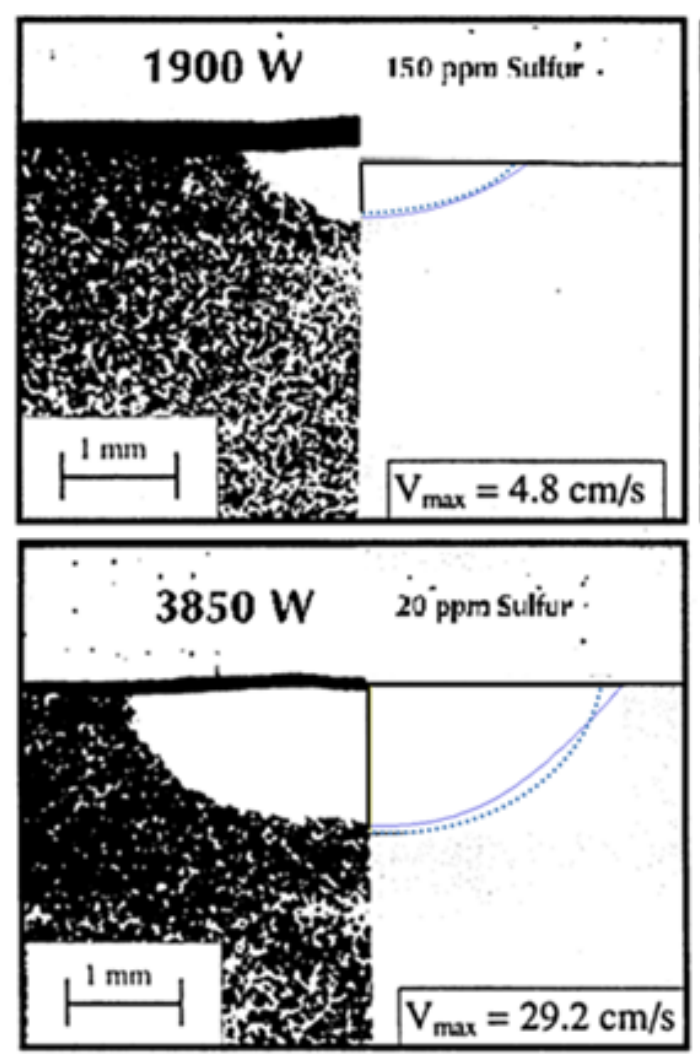

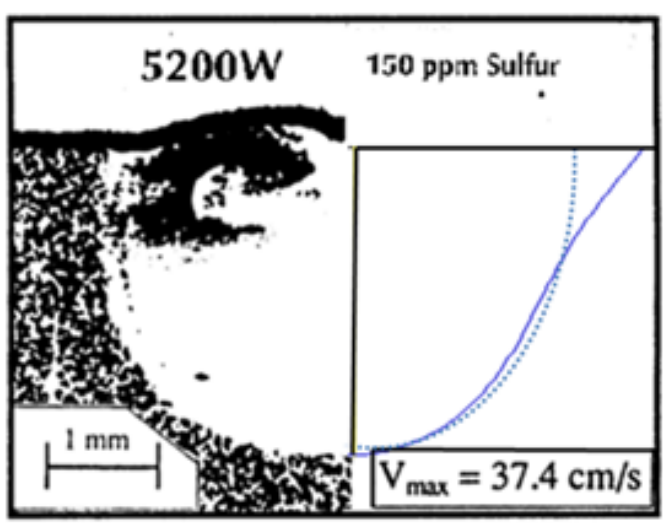

Pitscheneder et al.

Proposed Model

Figure 13. Simulation results with a positive surface tension temperature gradient input 


\section{GTAW Experiments}

Titanium alloy Ti-5Al-5Mo-5V-3Cr were spot welded in an incrementing time step of $1 \mathrm{~s}$ for 5 steps for 40A; then starting at $0.5 \mathrm{~s}$, next from $1 \mathrm{~s}$ to $5 \mathrm{~s}$ in $1 \mathrm{~s}$ time steps for $60 \mathrm{~A}$ welds as shown in Fig. 14. Samples of metallography indicating the fusion zones are illustrated in Fig. 15.

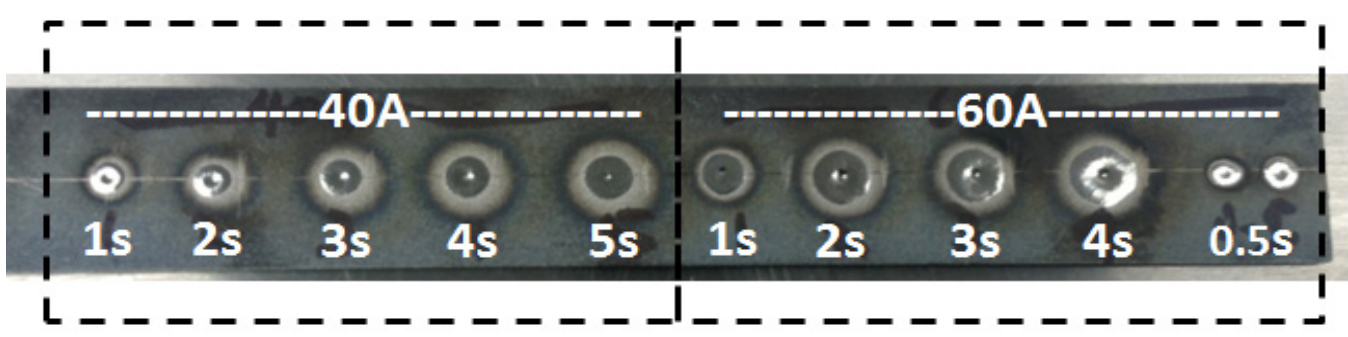

Figure 14. Ti-5Al-5Mo-5V-3Cr sample after spot welding of two current settings
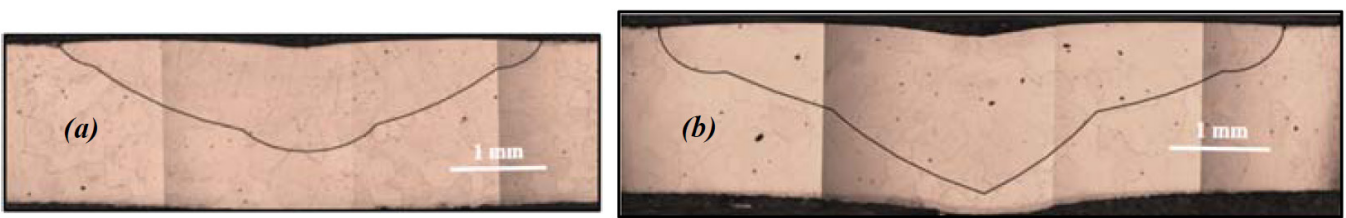

Figure 15. Examples of Ti-5Al-5Mo-5V-3Cr fusion zone metallography; (a) 10V \& 40A for 5 seconds; (b) $10 \mathrm{~V} \& 60 \mathrm{~A}$ for 3 seconds.

\section{Simulation Result}

\subsection{Model Inputs \& Associated Uncertainties}

Table 3. Key thermal properties of Ti-5Al-5Mo-5V-3Cr [32]

\section{Material Properties}

\begin{tabular}{c|rl}
$\rho$ & 4620 & $\mathrm{~kg} / \mathrm{m}^{3}$ \\
$T_{m}$ & 1963 & $\mathrm{Kelvin}$ \\
$\mu$ & $4.9 \times 10^{-3}$ & $\mathrm{~kg} / \mathrm{m} \cdot \mathrm{s}$ \\
$L$ & $3.65 \times 10^{5}$ & $\mathrm{~J} / \mathrm{kg}$ \\
$\beta$ & $1.1 \times 10^{-5}$ & $\mathrm{~K}$ \\
$\varepsilon$ & 0.63 &
\end{tabular}

Table 4. Temperature dependent data for specific heat and thermal conductivity of Ti-5Al-5Mo-5V-3Cr [33]

\begin{tabular}{|c|cccccccccc|c|}
\hline $\boldsymbol{T}$ & 20 & 100 & 200 & 300 & 400 & 500 & 600 & 700 & 800 & 900 & Kelvin \\
\hline $\boldsymbol{C} p$ & - & $\mathbf{5 2 3}$ & $\mathbf{5 6 5}$ & $\mathbf{5 8 6}$ & $\mathbf{6 4 9}$ & $\mathbf{7 1 2}$ & $\mathbf{7 9 5}$ & $\mathbf{8 7 9}$ & $\mathbf{8 6 3}$ & - & $\mathrm{J} / \mathrm{kg} \cdot \boldsymbol{K}$ \\
$\boldsymbol{k}$ & $\mathbf{8 . 3 2}$ & $\mathbf{9 . 2 1}$ & $\mathbf{1 0 . 5}$ & $\mathbf{1 1 . 7}$ & $\mathbf{1 3 . 4}$ & $\mathbf{1 4 . 6}$ & $\mathbf{1 5 . 9}$ & $\mathbf{1 7 . 2}$ & $\mathbf{1 8 . 4}$ & $\mathbf{1 9 . 7}$ & $\mathrm{J} / \boldsymbol{m} \cdot \boldsymbol{s} \cdot \boldsymbol{K}$ \\
\hline
\end{tabular}


Stenbacka et al. [34] did a review of arc efficiency values used for up-to-date GTAW simulations, they found under direct current and negative electrode (DCEN) welding conditions, the arc efficiency values were between $36 \%$ and $90 \%$; their study also suggested that with a $95 \%$ confidence, the arc efficiency for GTAW DCEN was approximated to be around $73-82 \%$, or $78 \%$ in average. Thus the assumption for the welding efficiency for this model was based on their findings, with an estimated efficiency of $78 \%$.

Table 5. Operating parameters of the simulations $[34,36]$

\begin{tabular}{|c|rl|}
\hline Operating Conditions & & \\
\hline$\eta$ & 78 & $\%$ \\
$V$ & 10 & Volts \\
$I$ & $40 \& 60$ & $\mathrm{Amps}$ \\
$\mu_{m}$ & $1.26 \times 10^{-6}$ & $\mathrm{H} / \mathrm{m}$ \\
$Z_{L}$ & $1.6 \mathrm{~mm}$ \\
$\sigma_{j}$ & $0.8 \& 1.2 \mathrm{~mm}$ \\
$h_{c}$ & 80 & $\mathrm{~W} / \mathrm{m}^{2} \cdot K$ \\
$\sigma_{b}$ & $5.67 \times 10^{-8}$ & $\mathrm{~W} / \mathrm{m}^{2} \cdot \mathrm{K}^{4}$ \\
$T_{a}$ & 300 & $\mathrm{Kelvin}$ \\
$P_{a}$ & 101.325 & $\mathrm{kPa}$ \\
\hline
\end{tabular}

The current distribution parameter $\left(\sigma_{\mathrm{j}}\right)$ on the other hand, is more troublesome since very small variations of this value would yield highly dissimilar results, and is often hardly practical to measure experimentally [35]. Saedi and Unkel [36] researched into the correlation between welding current and the current distribution parameter, their paper revealed a positive relationship between the two; as current increased, the distribution parameter went up consequently. And according to their results, for a low current situation (40 $60 \mathrm{~A}$ ), the current distribution parameter would sit around 1 $\mathrm{mm}$, and therefore was assumed to be $0.8 \mathrm{~mm}$ at $40 \mathrm{~A}$ and 1.2 $\mathrm{mm}$ at $60 \mathrm{~A}$.

Anyhow, without effective experimental and numerical procedures done to, e.g. arc efficiency, current distribution parameter and convective heat transfer coefficient etc. to model these parameters more accurately, the simulation results would contain considerable extent of uncertainties and seemingly biased.

\subsection{Sensitivity of Enhancement Factor}

\section{Effect of EF on Weld Pool Geometry}

First, by increasing the thermal conductivity and viscosity, the width of the pool saw a general declining trend regardless of the degree of surface tension temperature gradient. This may be due to increased viscosity; therefore there would be more resistance in flow movement.

As for the pool depth, the raised viscosity still dictated the flow for positive gradients, restricting the pool penetration; whereas for negative gradients, the pool depth went up, the improved conductivity along with the enhanced outward flow Marangoni Effect (more momentum to dive to the bottom) would thus aid penetration. Overall, the pool aspect ratio was identical to the change of pool penetration, suggesting the incorporation of enhancement factor would help to penetration more than spreading the pool further away from the centre. 

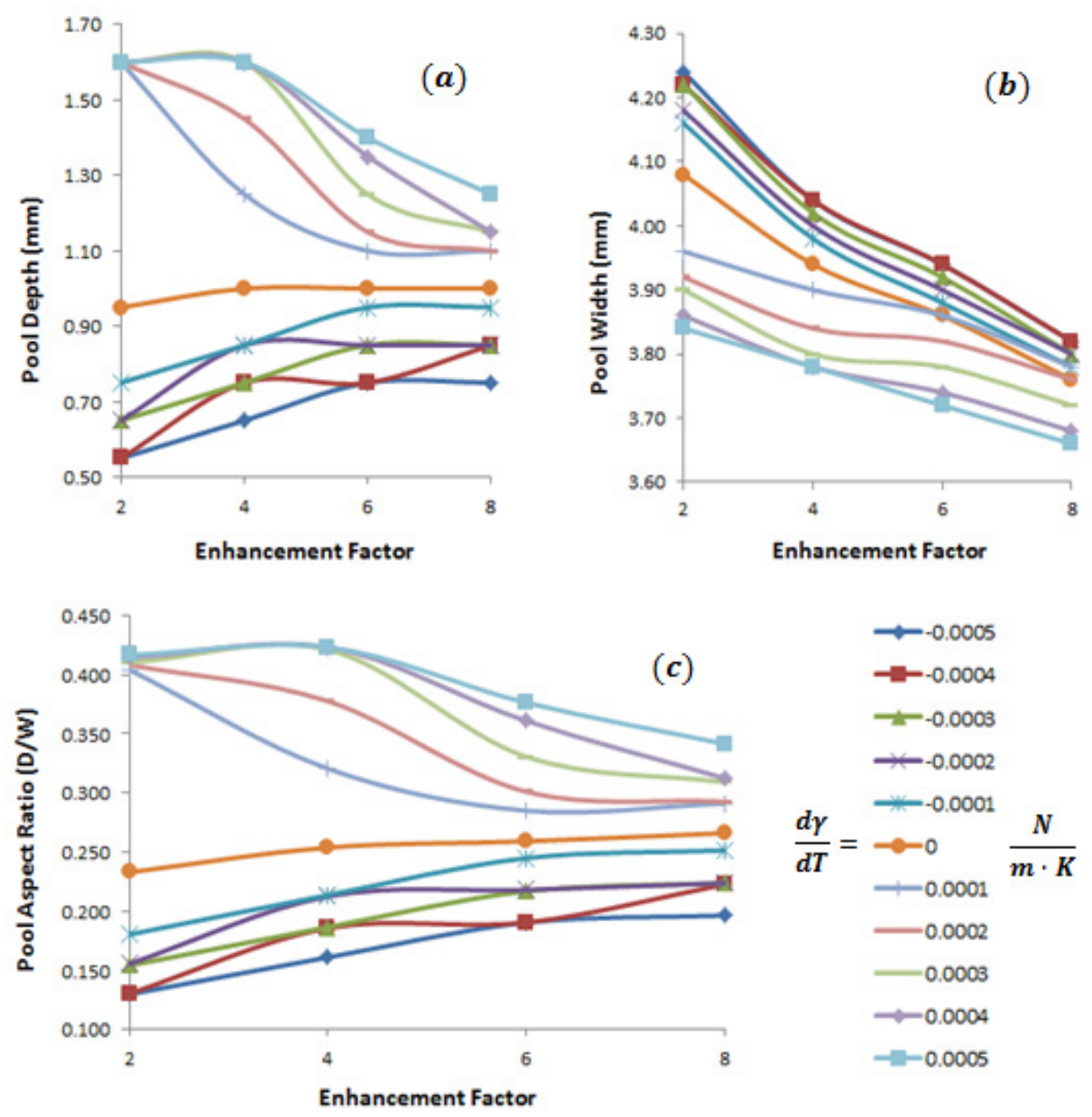

Figure 16. Effect of EF on the pool geometry under 40A for 3s (a) width; (b) depth; (c) aspect ratio

\section{Effect of EF on Weld Pool Temperature}

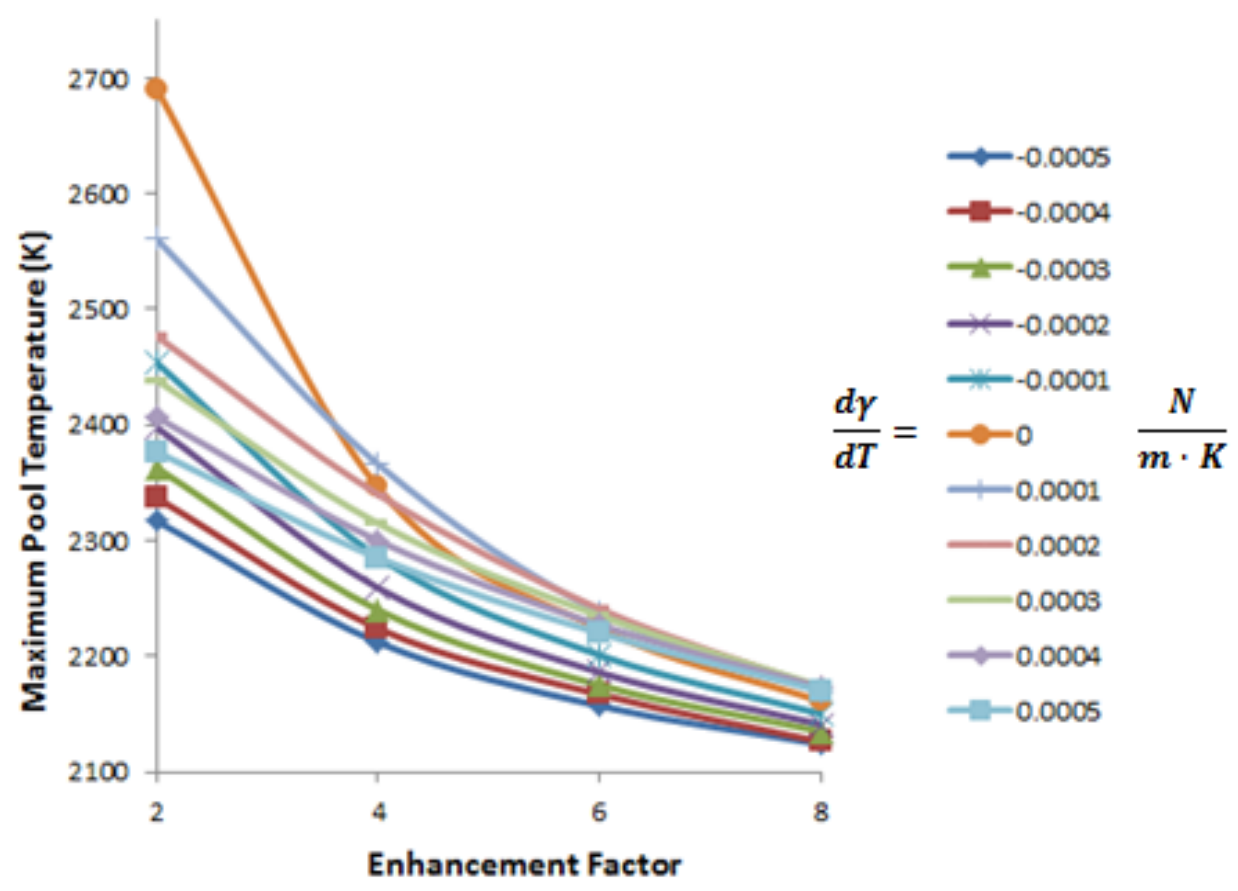

Figure 17. Effect of EF on the maximum pool temperature under $40 \mathrm{~A}$ for $3 \mathrm{~s}$ 
Highest pool temperature was recorded when surface tension force was absent (at $\mathrm{d} \gamma / \mathrm{dT}=0$ ), so much less convective heat transfer (high viscosity) which was replaced by high conductivity, or in another word heat is more focused at the pool centre. Since positive gradients would induce inward flows, this would also concentrate the heat to the centre, hence also producing high temperatures. Overall, with increasing enhancement factors, the maximum pool temperature declined, this would coincide with the general decreasing in pool size.

\subsection{Sensitivity of $d \gamma / d T$}

Sensitivity analysis on the model was performed with varying degree of surface tension temperature gradients from -0.0005 to $0.0005 \mathrm{~N} / \mathrm{m} \cdot \mathrm{K}$ in steps of $0.0001 \mathrm{~N} / \mathrm{m} \cdot \mathrm{K}$; its influence on the maximum weld pool temperature, maximum fluid velocity (negative being outward flow) and the weld pool aspect ratio were investigated as demonstrated in Fig. 18 \& Fig. 19.

\section{Effect of $d \gamma / d T$ on Weld Pool Geometry}

As one would expect, by varying the surface tension thermal gradient from negative to positive, the weld pool geometry went from wide and shallow to deep and narrow; also the width, depth and aspect ratio tends to increase/decrease in a linear pattern, without any critical points as seen in Fig. 18.

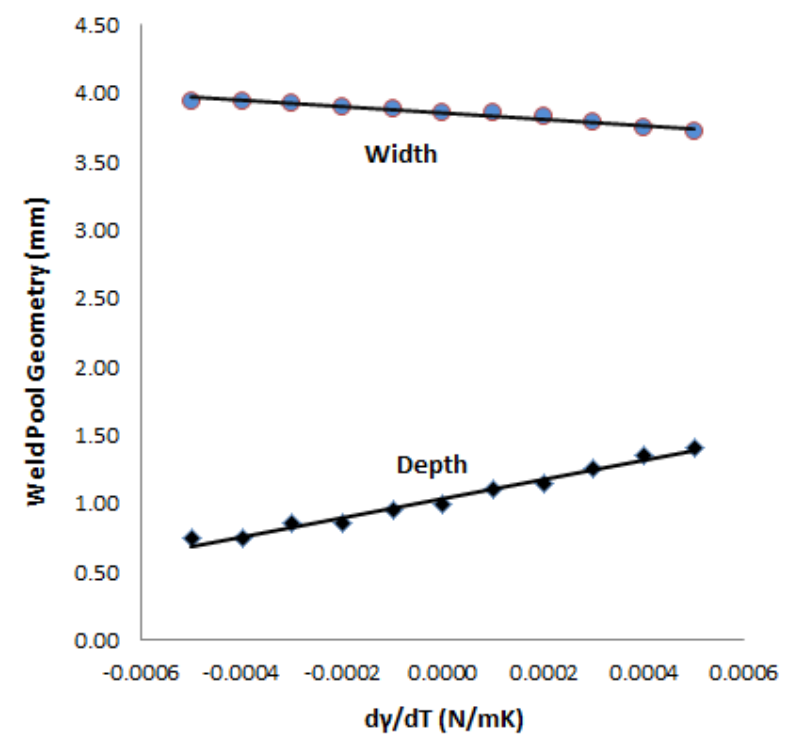

(a)

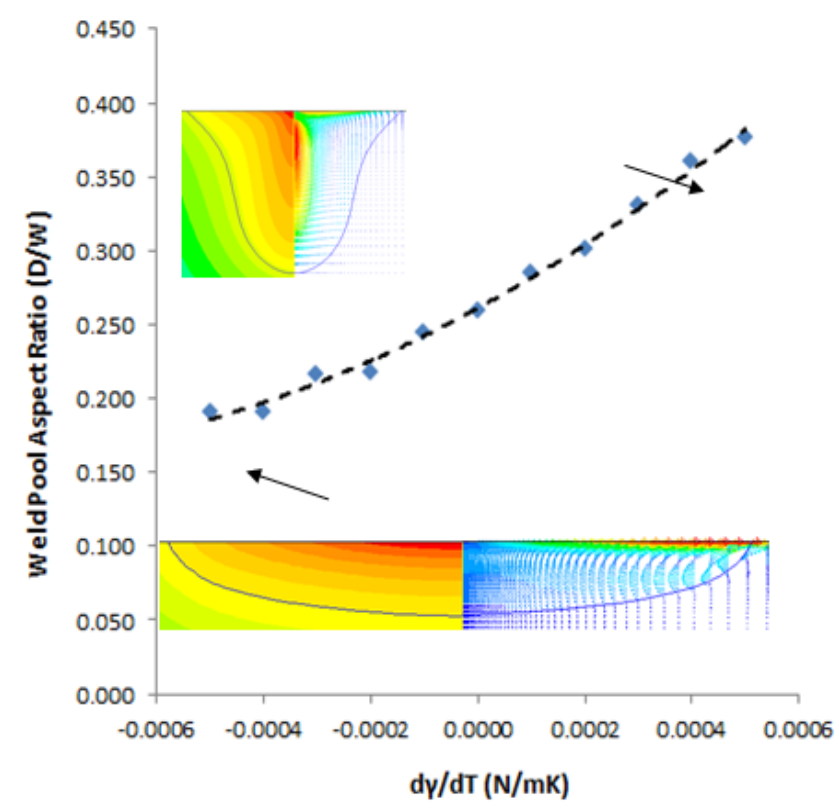

(b)

Figure 18. Influence of $\partial \gamma / \partial T$ on the weld pool geometry: (a) size of width and depth; (b) pool aspect ratio $(\mathrm{D} / \mathrm{W})$.

\section{Effect of $d \gamma / d T$ on Weld Pool Temperature \& Flow Velocity}

The weld pool temperature gradually increased as the surface tension thermal gradient moved towards zero, where the maximum temperature peaked usually high as seen in Fig. 19 (a). With absence of surface tension force, thermal mixing stimulating conductivity could not be fully utilised, instead localising the heat transfer inducing higher weld pool temperature and buoyancy force.

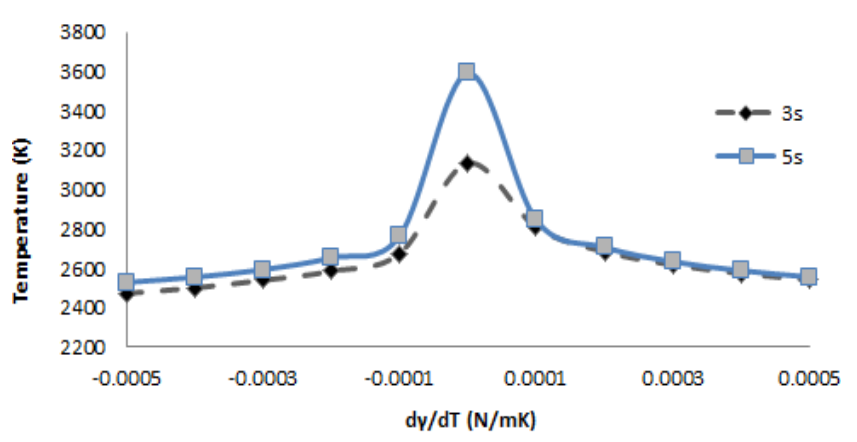

(a) 


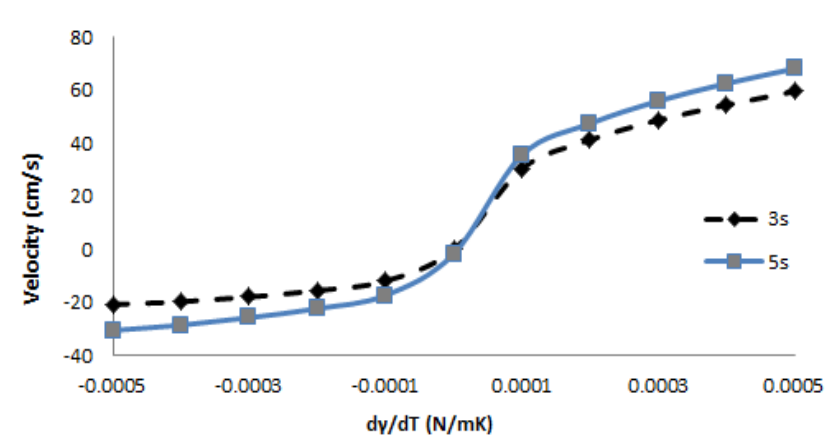

(b)

Figure 19. Variations of $\partial \gamma / \partial T$ under $40 \mathrm{~A}$ with respect to: (a) maximum weld pool temperature; (b) maximum fluid velocity.

Furthermore, by examining the effect of surface tension temperature gradient on the flow velocities, interesting observations on the magnitude of the forces associated with the weld pool could be revealed. At $\partial \gamma / \partial \mathrm{T}=0$, a very small negative (outward flow) velocity was usually induced, less than $2 \mathrm{~cm} / \mathrm{s}$ in magnitude, reinforcing the theory that for GTAW process, surface tension forces would have the most profound impact; the outward flow direction suggests that buoyancy forces (outward flow) would outweigh electromagnetic force (inward flow), since these are the only two forces existing in this model. Moreover, the velocity magnitudes for positive gradients are much larger than when negative, this may be due to the fact that gravitational force would stimulate the inward flow, further speeding up the circulating flow initiated from the top surface.

\section{Comparison of Results}

\subsection{Flow Regime}
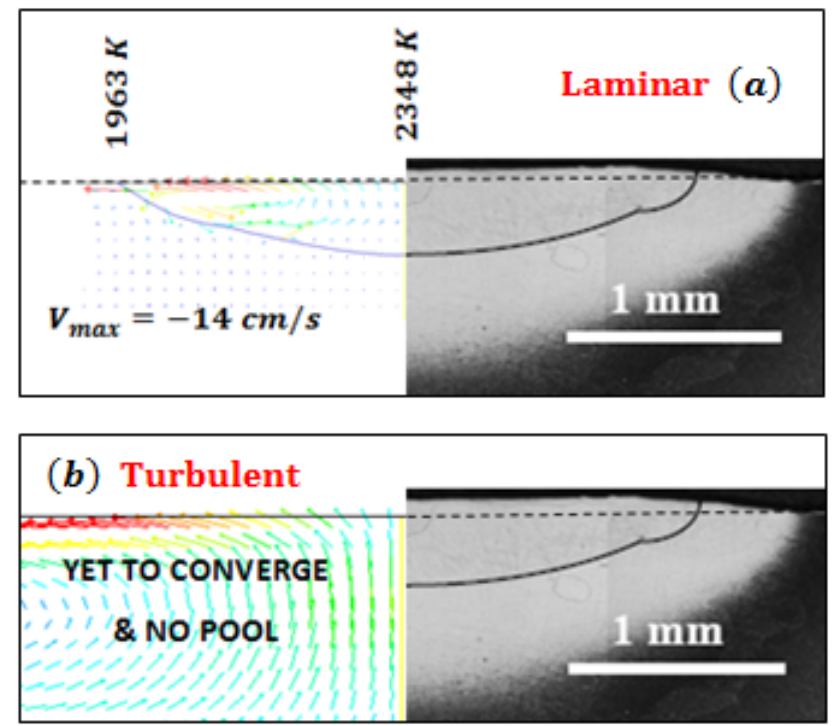

Figure 20. Comparison of results between (a) laminar flow scheme; (b) original turbulent flow assumption; under $60 \mathrm{~A}$ power for 0.5 seconds \& EF $=2 \& \mathrm{~d} \gamma / \mathrm{dT}=-0.00042 \mathrm{~N} / \mathrm{m} \cdot \mathrm{K}$
As explained in introduction, the laminar or turbulent assumption has always been at the centre of numerical welding researches, and for past studies, researchers had assumed the pool to be either consistently laminar or turbulent, with no crossovers of these two; Whereas this time, the model was converted based on laminar flow assumptions at shorter welding times, and saw the breakthrough in predicted weld pool geometry.

Under the $60 \mathrm{~A}$ power setting, with a $k-\varepsilon$ turbulent assumption, the weld pool would not even appear if the welding time was set to $0.5 \mathrm{~s}$, as shown in Fig. 20 (b). On the other hand, with a laminar flow setup, the model was able to produce "bang on" predictions of the overall weld pool shape.

Having proved that during the early stages of the weld pool formation, laminar flow assumption would be more appropriate, but there must be a period of transition to turbulent flow. Fig. 21 is illustrating the results under the same $60 \mathrm{~A}$ welding current, with time progressed to 2 seconds, none of which had brilliant match with the experimental results. The laminar assumption was over predicting the weld pool shape; hence the stream had already gone past the laminar flow guess. At the same time, turbulent assumption would under calculate the pool size by a large fraction. These combined would imply that the pool at the 2 -second instant is probably undergoing laminar to turbulent transition, thus no viable match could be realised given keeping all else constant.

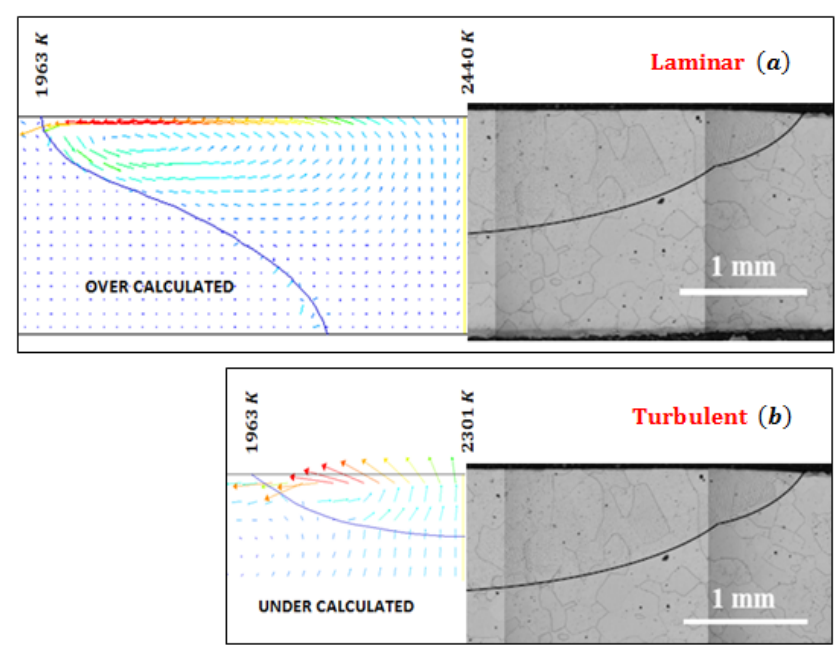

Figure 21. Comparison of results between (a) laminar flow scheme; (b) original turbulent flow assumption; under $60 \mathrm{~A}$ power for 2 seconds; $\mathrm{EF}=2$ $\& \mathrm{~d} \gamma / \mathrm{dT}=-0.00042 \mathrm{~N} / \mathrm{m} \cdot \mathrm{K}$

This finding gave clear suggestions that, the "constant" turbulent assumptions found in previous studies, would underestimate the pool size at the initial stage of applied weld arc, while vice versa for the laminar guess. By simulating the weld pool in laminar flow conditions at the start, and then apply turbulent flow regime to latter welding times would improve the simulation results quite considerably. Fig. 22 is showing excellent agreement under turbulent flow at $3 \mathrm{~s}$. 


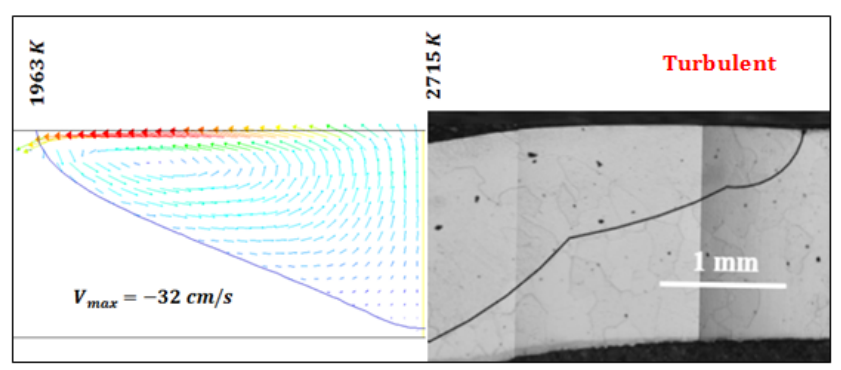

Figure 22. Good agreement of overall pool shape with turbulent flow regime; under $60 \mathrm{~A}$ for 3 seconds; at $\mathrm{EF}=2 \& \mathrm{~d} \gamma / \mathrm{dT}=-0.00042 \mathrm{~N} / \mathrm{m} \cdot \mathrm{K}$

\subsection{Estimation of $d \gamma / d T$ and $E F$ for Ti-5Al-5Mo-5V-3Cr}

As for the current study, the weld pool shape had a good agreement with an enhancement factor of 2, negative surface tension temperature gradients was also discovered with slight variations for the two power settings, $-0.00035 \mathrm{~N} /$ $\mathrm{m} \cdot K$ for the $40 \mathrm{~A}$ case and $-0.00042 \mathrm{~N} / \mathrm{m} \cdot K$ under the 60 A scenario.

\section{Conclusions}

A simulation model of GTAW process has been developed in this paper to investigate the weld pool shape variations due to Marangoni effect and surface tension shear stress. Based on the results, by enhancing the liquid thermal conductivity and viscosity simultaneously, the weld pool size shrank, so does the pool temperature and flow velocity, suggesting the added resistance to flow by viscosity would object the heat transfer more than conductivity, confirming the weld pool shape would be more sensitive to changes in viscosity than thermal conductivity, reinforcing convective heat transfer would be more significant than conductive heat transfer.

By varying the $d \gamma / d T$ value from negative to positive, the weld pool geometry went from wide and shallow to deep and narrow; the pool width, depth, and aspect ratio tend to increase/decrease linearly with no critical points for Ti-5Al-5Mo-5V-3Cr. With the absence of Marangoni Effect $(\mathrm{d} \gamma / \mathrm{dT}=0)$, a tiny negative (outward flow) velocity vector was present, made up by buoyancy effect (outward flow) and electromagnetic force (inward flow); this would settle that Marangoni Effect being the most dominant force in shaping the weld pool, followed by buoyancy effect and electromagnetic force under the GTAW process. Titanium alloy $\mathrm{Ti}-5 \mathrm{Al}-5 \mathrm{Mo}-5 \mathrm{~V}-3 \mathrm{Cr}$ under investigation was found to constitute high negative $\partial \gamma / \partial \mathrm{T}$ values during GTAW process, overall good agreement of simulation results to experimental data was obtained by a relatively low enhancement factor of 2 .

\section{Acknowledgements}

This work was sponsored by School of Engineering, Auckland University of Technology, New Zealand.

\section{REFERENCES}

[1] DebRoy, T. \& David, S.A., (1995). Physical processes in fusion welding. Reviews of Modern Physics. Vol.67, Issue 1, p85-112.

[2] Limmaneevichitr, C., (2000). Flow visualization of Marangoni convection in simulated weld pools. Ph.D. dissertation. University of Wiscousin-Madison, USA.

[3] Katayama, S. et al., (2001). X-ray transmission in-situ observation of fluid flow inside molten pool during tig arc welding of stainless steel. Transactions of JWRI. Special Issue: 3rd International Conference of High Temperature Capillarity 2000. Vol.30.

[4] Berthier, A., Paillard, P., Carin, M., Valensi, F., Pellerin, S. (2012) TIG and a-TIG welding experimental investigations and comparison to simulation part 1: Identification of Marangoni effect. Science and Technology of Welding and Joining 17(8): 609-615.

[5] Xia, D., Xu, B.-S., Lv, Y.-H., Yi, J., Liu, C.-L. (2012) Effect of Marangoni convection on welding pool of plasma direct metal forming finite element model. Materials Science Forum 704-705: 674-679.

[6] Sándor, T., Mekler, C., Dobránszky, J., Kaptay, G. (2013) An improved theoretical model for A-TIG welding based on surface phase transition and reversed Marangoni flow. Metallurgical and Materials Transactions A: Physical Metallurgy and Materials Science 44(1): 351-361.

[7] Traidia, A., Roger, F. \& Guyot, E., (2010). Optimal parameters for pulsed gas tungsten arc welding in partially and fully penetrated weld pools. International Journal of Thermal Science. Vol.49, Issue 7, p1197-1208.

[8] De, A. \& DebRoy, T., (2004). A smart model to estimate effective thermal conductivity and viscosity in the weld pool. Journal of Applied Physics. Vol.95, Issue 9, p5230-5240.

[9] Vowell, S., (2009). Microfluids: the effects of surface tension. Physics department, University of Washington, USA.

[10] Bragard, J. \& Velarde, M.G., (1998). Benard-Marangoni convection: planforms and related theoretical predictions. Journal of Fluid Mechanics. Vol.368, p165-194.

[11] Ehlen, G., Ludwig, A. \& Sahm, P.R., (2003). Simulation of Time-dependent pool shape during laser spot welding: transient effects. Metallurgical and Materials Transactions A. Vol.34A, p2947-2961.

[12] Aidun, D. \& Martin, S., (1997). Effect of sulphur and oxygen on weld penetration of high-purity autenitic stainless steels. Journal of Materials Engineering and Performance. Vol.6, p496-502.

[13] Heiple, C.R. et al., (1983). Surface active element effects on 
the shape of the gta, laser and electron beam welds. Welding Journal. Vol.62, Issue 3, p72.

[14] Limmaneevichitr, C. \& Kou, S., (2000). Experiments to simulate effect of Marangoni convection on weld pool shape. Welding Research Supplement. P231-237.

[15] Sahoo, P., DebRoy, T. \& McNallan, M., (1988). Surface tension of binary metal - surface active solute systems under conditions relevant to welding metallurgy. Metallurgical Transactions B. Vol.19, p483-491.

[16] Kou, S. \& Sun, D.K., (1985). Fluid flow and weld penetration in stationary arc welds. Metallurgical Transaction A. Vol.16A, Issue 2, p203-213.

[17] Kou, S. \& Wang, Y.H., (1986). Weld pool convection and its effect. Welding Journal. Vol.65, Issue 3, p63-70.

[18] Kumar, A. \& DebRoy, T., (2005). Tailoring complex weld geometry through reliable heat transfer and fluid flow caluclations and a genetic algorithm. Metallurgical and Materials Transactions A. Vol.36A, p2725-2735.

[19] ] Shi, Y. et al., (2011). Numerical simulation of the force in TIG welding pool based on Fluent. Electric Welding Machine. Vol.41, Issue 9, p21-24.

[20] Kou, S., (1987). Welding metallurgy. New York: Wiley.

[21] Lee, H.G. \& Kim, J., (2012). A comparison study of the Boussinesq and the variable density models on buoyancy-driven flows. Journal of Engineering Mathematics. Vol.75, Issue 1, p15-27.

[22] Lin, M.L. \& Eagar, T.W., (1986). Pressures produced by gas tungsten arcs. Metallurgical Transactions B. Vol.17B, p601-607.

[23] Choo, T.C. \& Szekely, J. (1991). The effect of gas shear stress on Marangoni flows in arc welding. Welding Research Supplement. P223-233.

[24] Matsunawa, A. \& Yokoya, S., (1989). Fluid flow and its effect on penetration shape in stationary arc welds. Recent Trends in Welding Science and Technology. Proceedings from 2nd International Conference, Gatlinburg. ASM International.

[25] Fluent ${ }^{\circledR}$ Tutorial Guide. ANSYS ${ }^{\circledR} .2009$.
[26] Brent, A., Voller, V. \& Reid, K., (1988). Enthalpy-porosity technique for modelling convection-diffusion phase change: application to the melting of pure metal. Numerical Heat Transfer B. Vol.13, p297-318.

[27] Patankar, S.V., (1980). Numerical heat transfer and fluid flow. Hemisphere, New York, USA.

[28] Voller, V.R., \& Swaminathan, C.R., (1991). General source-based method for solidification phase change. Numerical Heat Transfer Part B Fundamentals. Vol.19, Issue 2, p175-189.

[29] De, A. \& DebRoy, T., (2005). Reliable calculations of heat and fluid flow during conduction mode laser welding through optimization of uncertain parameters. Welding Journal. Vol.84, Issue 7, p101-112.

[30] Hong, K. et al., (2002). Modelling turbulent thermofluid flow in stationary gas tungsten arc weld pools. Science and Technology of Welding and Joining. Vol.7, Issue 3, p125-136.

[31] Pitscheneder, W. et al., (1996). Role of sulphur and processing variables on the temporal evolution of weld pool geometry during multi-kilowatt laser beam welding of steels. Supplement to the Welding Journal. p71.

[32] Luo, L. et al, (2009). Brief introduction for BT22 titanium alloy. Journal of Hot Working Technology. Vol.38, Issue 14, p14-16.

[33] Department of Physical Engineering, Marochnik. (2013). Database of Steel and Alloy: VT22. Retrieve on 19 Aug 2013 from:

http://www.splav.kharkov.com/en/e mat_start.php?name id $=1302$

[34] Stenbacka, N., Choquet, I. \& Hurtig, K., (2012). Review of arc efficiency values for gas tungsten arc welding. Intermediate Meeting BAM.

[35] Pierce, S.W., Burgardt, P. \& Olsen, D.L., (1999). Thermocapillary and arc phenomena in stainless steel welding. Welding Research Supplement, p45-52.

[36] Saedi, H.R. \& Unkel, W., (1988). Arc and weld pool behaviour for pulsed current GTAW. Welding Research Supplement. p247-255. 